\title{
Identification of a major quantitative trait locus underlying salt tolerance in 'Jidou 12' soybean cultivar
}

\author{
XiaoLei Shi ${ }^{1 \dagger}$, Long Yan ${ }^{1,2+}$, ChunYan Yang ${ }^{1 \dagger}$, WeiWen Yan ${ }^{1}$, David Octor Moseley ${ }^{2}$, Tao Wang ${ }^{1}$, BingQiang Liu', \\ Rui Di ${ }^{1}$, PengYin Chen ${ }^{2}$ and MengChen Zhang ${ }^{1 *}$
}

\begin{abstract}
Background: Identification of the quantitative trait locus $(\mathrm{QTL})$ underlying salt tolerance is a prerequisite for markerassisted selection in the salt-tolerant breeding process.

Methods: In this study, the recombinant inbred lines derived from the salt-tolerant elite soybean cultivar 'Jidou 12' and the salt-sensitive elite cultivar'Ji NF 58' were used to identify the QTL associated with salt tolerance, using both salt tolerance rating (STR) and leaf chlorophyll content (SPAD) as indicators.

Results: A major salt-tolerant QTL, which was flanked by SSR markers GMABAB and Barcsoyssr_03_1421 on chromosome 3, was identified based on single-marker regression, single trait composite interval mapping, and multiple interval mapping analysis. For STR, the LOD ranged from 19.8 to $20.1 ; R^{2}$ ranged from 44.3 to $44.7 \%$; and the additive effect ranged from 0.876 to 0.885 among the three mapping methods. For SPAD, the LOD ranged from 10.6 to $11.0 ; R^{2}$ ranged from 27.0 to $27.6 \%$; and the additive effect ranged from 1.634 to 1.679 among the three mapping methods.
\end{abstract}

Conclusions: In this study, a major QTL conditioning salt tolerance on chromosome 3 was identified. The DNA markers closely associated with the QTLs might be useful in marker-assisted selection for soybean salt tolerance improvement in Huanghuaihai, China.

Keywords: Soybean, Salt-tolerant, QTL, STR, SPAD

\section{Background}

Salinity is one of the major abiotic stress factors that significantly reduces crop yields. Approximately $20 \%$ of irrigated land is affected by salt stress around the world [1]. It has been estimated that $6.62 \%$ of the arable land was affected by salt stress in China. Development of salt-tolerant crops will be required to improve the sustainability of crop production.

\footnotetext{
*Correspondence: mengchenzhang@hotmail.com

${ }^{\dagger}$ XiaoLei Shi, Long Yan and ChunYan Yang contributed equally to this work

${ }^{1}$ Institute of Cereal and Oil Crops, Hebei Academy of Agricultural and Forestry Sciences/Shijiazhuang Branch Center of National Center for Soybean Improvement/Huang-Huai-Hai Key Laboratory of Biology and Genetic Improvement of Soybean, Ministry of Agriculture/Key Laboratory of Crop Genetics and Breeding, Shijiazhuang 050035, China Full list of author information is available at the end of the article
}

Soybeans are an important crop for food, feed, and biodiesel production due to their high oil and protein content. Soybean is considered a moderately salt-sensitive crop [2]. Salt stress will damage all developmental stages of soybean, including germination, plant growth [3], nodule formation [4], and seed yield [5]. The tolerant soybean cultivars had $37 \%$ higher yields than the susceptible cultivars [6]. Hence, development of salt tolerant soybean cultivars will be an effective way to maintain sustainable production in salt stressed regions. However, because there was a lack of a simple and cost effective way to precisely evaluate a large number of lines for salt tolerance during the selection process in breeding, the development of salt-tolerant soybean cultivars was hampered for a long time. Therefore, marker-assisted selection (MAS) may be a particularly good method for the salt tolerance breeding process. A prerequisite for MAS is knowledge 
of the genomic location and genetic effect of the major quantitative trait locus (QTL), which conditions salt tolerance in soybean. Two QTLs associated with salt tolerance have been mapped on chromosome 3 (Linkage group N) and chromosome 18 (Linkage group G). It has been reported that wild soybean accession PI 483463 [7], wild soybean accession JWS156-1 [8], wild soybean accession W05 [9], soybean cultivar S-100 [10], soybean cultivars FT-Abyara and Jin dou No. 6 [11], and soybean cultivar Tiefeng $8[12,13]$ contain the salt tolerant allele on chromosome 3 . Additionally, soybean cultivar Kefeng No.1 [14] contains the tolerant allele on chromosome 18.

The Huanghuaihai region was the second most important area for soybean production in China. The area of saline land is approximately 4.67 million hectares in the Huanghuaihai region [15]. Identification of the QTL conditioning salt tolerance in the elite cultivars that are adapted to this region will aid soybean breeding in this special area. Jidou 12 was an elite soybean cultivar in the Huanghuaihai region [16], widely used as a breeding parent [17] for its high yield [18], high protein content [19], and soybean mosaic virus (SMV) tolerance [20]. 'Ji NF 58' was a soybean cultivar in the Huanghuaihai region containing high oil content [16]. Based on the $\mathrm{Na}^{+}$content analysis in different organs at the seeding stage, 'Jidou 12' was considered to be a salt-tolerant cultivar while 'Ji NF 58 ' was a salt-susceptible soybean cultivar [15].

In this study, QTL analyses for salt tolerance were performed in a RIL population derived from 'Jidou 12' $\times$ 'Ji NF 58', to identify the QTL conditioning salt tolerance in 'Jidou 12' and to facilitate MAS soybean salt tolerance breeding in Huanghuaihai, China.

\section{Methods}

\section{Plant materials}

A RIL population, consisting of 156 lines derived from the cross 'Jidou 12' × 'Ji NF 58', was used to identify the QTL associated with salt tolerance. 'Jidou 12' was an elite high protein content cultivar, while 'Ji NF 58' was an elite high oil content cultivar. They were both bred at the Institute of Cereal and Oil crops, Hebei Academy of Agricultural and Forestry Sciences, Shijiazhuang, China. Seeds for the $\mathrm{F}_{2}$ generation were collected from a single $F_{1}$ plant in late September 2002. The RIL were advanced to the $F_{9: 10}$ generations by single-seed descent without any particular selection method.

\section{Evaluation of salt tolerance}

A salt-water flood method [21] was used to evaluate the salt tolerance of the RIL and their parents. In brief, five healthy plants of each cultivar/line were grown in a pot $(15 \times 15 \mathrm{~cm})$ filled with sand, and 8 pots were placed in a large plastic container $(65 \times 40 \times 15 \mathrm{~cm})$ containing half-strength Hoagland and Arnon nutrient solution. Two weeks after planting, the soybean plants were initially treated with $60 \mathrm{mM} \mathrm{NaCl}$. After 3 days, $\mathrm{NaCl}$ concentration was raised to $150 \mathrm{mM}$. The $\mathrm{NaCl}$ solution was replaced every 3 days and the concentration was maintained at the same level until the end of the experiment. The natural sunlight in the greenhouse was supplemented by high-pressure sodium light to provide 14-h photoperiod. The temperature was controlled by air conditioning to maintain the temperature at approximately $25 \pm 2{ }^{\circ} \mathrm{C}$. When the salt-sensitive soybean cultivar, Clark, showed clearly salt toxicity symptom (complete death), the salt tolerance rating (STR) for each genotype was evaluated by the chlorotic leaf of soybean plants. The STR scale was divided into five grades, ranging from 1 to 5 [11] (Fig. 1). Meanwhile, the chlorophyll content (SPAD value) of leaf from the same node number was measured using a chlorophyll meter (Konica Minolta SPAD-502). This SPAD value is proportional to the chlorophyll content in leaves. The evaluation for the RIL and parents was carried out in a greenhouse at the Institute of Cereal and Oil crops, Hebei Academy of Agricultural and Forestry Sciences, Shijiazhuang, China. The experiment consisted of a random block design with three replications. The entire experiment was carried out two times, independently of each other.

\section{DNA extraction and SSR analyses}

The young leaves from single plants for each $\mathrm{F}_{9}$ plant were collected for DNA extraction. Next, 357 SSR markers that were well distributed throughout the 20 soybean genetic linkage map [22-24] were selected to test the polymorphism between the parents of the population. Subsequently, 118 polymorphic SSR markers were used to analyze the population (Additional file 1: Table S1). SSR markers information were obtained from the SoyBase website of the USDA, ARS Genome Database (http://soybase.agron.iastate.edu/). DNA extraction and marker analysis were conducted following the protocols described by Wang et al. [25].

\section{Data analysis}

The statistical analyses for STR and SPAD were conducted using JMP Pro 11 (SAS Institute, Cary, NC). The genetic linkage map based on the polymorphism markers was constructed by using the Map Manager program QTXb20 (http://mapmgr.roswellpark.org/mapmgr.html), with the selection of Kosambi for the Map Function and a 0.01 probability for the linkage criterion. The candidate QTL controlling salt tolerance was identified by singlemarker regression (SMR), single trait composite interval mapping (CIM), and single trait multiple interval mapping (MIM) analyses using QGene 4.3.10 [26]. QTL LOD 


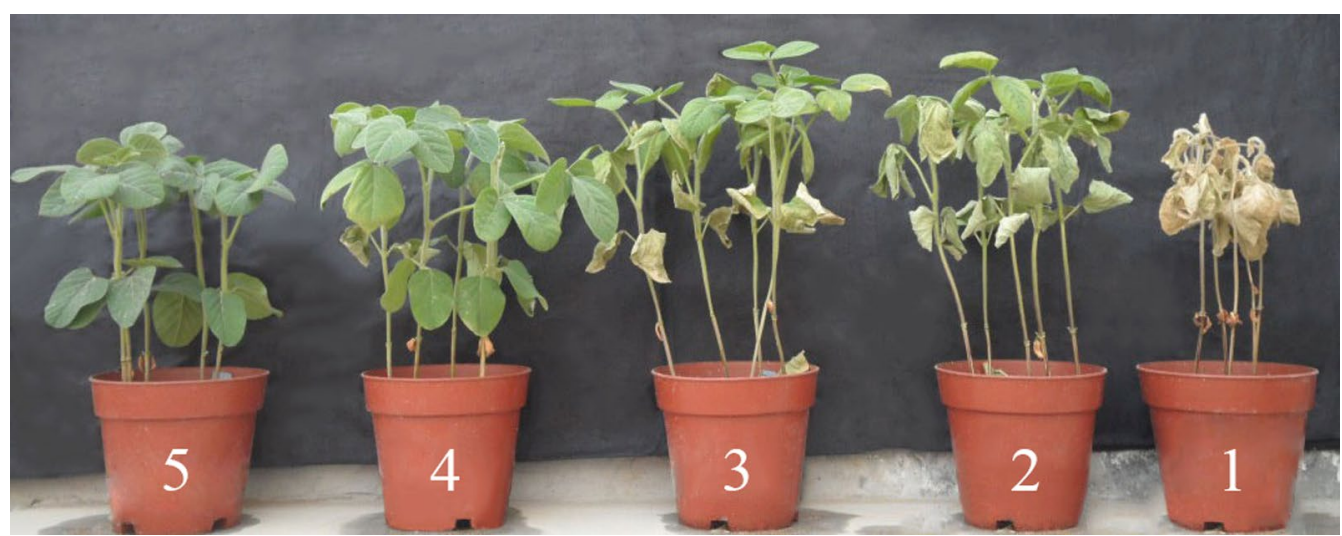

Fig. 1 Salt tolerance rating (STR) of the progeny derived from 'Jidou 12' x 'Ji NF 58'. 1, plants completely died; 2, two-thirds or more leaves showed chlorotic symptoms or only upper leafs survived; 3 , half or fewer leaves showed chlorotic symptoms; 4 , one-third or fewer leaves showed chlorotic symptoms; 5 , plants grew normally

levels higher than 2.5 were significant. The LOD plots were created by MapChat 2.2 [27] based on the data from QTXb20 and QGene.

\section{Results and discussion}

'Jidou 12' showed significantly ( $\mathrm{P} \leq 0.01)$ higher salt tolerance than 'Ji NF 58' for both STR and SPAD. The STR of 'Jidou 12' was 4.0 while it was 1.5 for 'Ji NF 58.' The SPAD of 'Jidou 12' was 40.6 while it was 36.5 for 'Ji NF 58'. Continuous distribution and transgressive segregation of the STR and SPAD were observed in the RILs (Fig. 2). For the 156 RILs, the STR ranged from 1.0 to 5.0, with an average of 2.79, and the SPAD ranged from 30.5 to 49.2, with an average of 37.1. There was a significant positive correlation $(\mathrm{r}=0.659, \mathrm{P} \leq 0.01)$ between the STR and SPAD values.

The linkage map of 'Jidou 12' × 'Ji NF 58', consisting of 118 SSR markers and covering a total distance of 1008.4 cM on 20 linkage groups, was established. The average distance between two markers was $8.5 \mathrm{cM}$. Only one QTL for both STR and SPAD was detected on chromosome 3, using the averaged data by SMR, CIM, and MIM (Table 1 and Fig. 3). For STR using SMR, this QTL was closely linked with SSR marker Sat_091. The LOD was 19.8, and the QTL could explain $44.3 \%$ of the total phenotype variance. The additive effect of this QTL was 0.876. For STR using CIM, this QTL was flanked by SSR markers GMABAB and Barcsoyssr_03_1421 while it was closely linked with SSR marker Sat_091. The LOD was 19.8 , and the QTL could explain $44.3 \%$ of the total phenotype variance. The additive effect of this QTL was 0.877. For STR using MIM, this QTL was closely linked with SSR marker Sat_091. The LOD was 20.1, and the QTL could explain $44.7 \%$ of the total phenotype variance. The additive effect of this QTL was 0.885 . For SPAD using SMR, this QTL was closely linked with SSR marker Sat_091. The LOD was 10.7, and the QTL could explain $27.0 \%$ of the total phenotypic variance. The additive
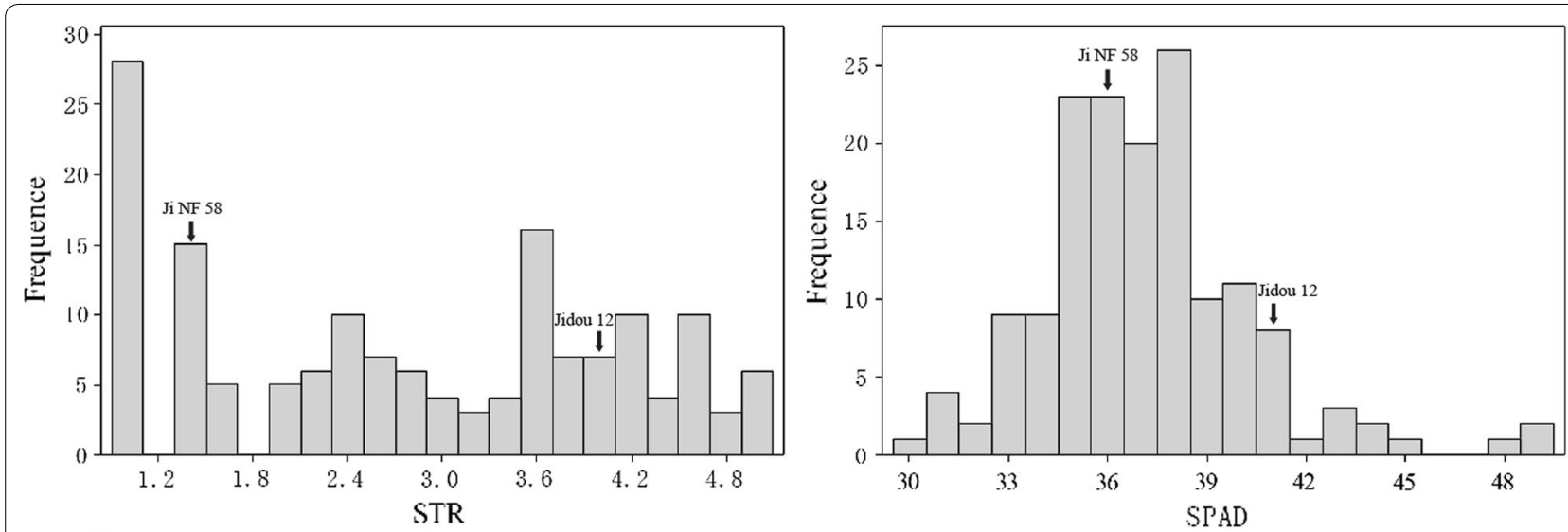

Fig. 2 Frequency distribution of salt tolerance rating (STR) and leaf chlorophyll content (SPAD) for RILs derived from 'Jidou 12' $\times$ 'Ji NF 58' 
Table 1 QTL analysis of salt tolerance rating (STR) and leaf chlorophyll content (SPAD) values for RIL derived from 'Jidou 12 ' x 'Ji NF 58' using different mapping method

\begin{tabular}{lllllll}
\hline Trait & Method & Nearest marker & Position (cM) & LOD & $\mathbf{R}^{\mathbf{2}(\%)^{\mathbf{a}}}$ & Additive $^{\mathbf{b}}$ \\
\hline STR & SMR & Sat_091 & 38.3 & 19.8 & 44.3 & 0.876 \\
& CIM & Sat_091 & 38.3 & 19.8 & 44.3 & 0.877 \\
& MIM & Sat_091 & 38.3 & 20.1 & 44.7 & 0.885 \\
SPAD & SMR & Sat_091 & 38.3 & 10.7 & 27.0 & 1.634 \\
& CIM & Sat_091 & 38.3 & 10.7 & 27.0 & 1.636 \\
& MIM & Satt237/Satt255 & 35.5 & 11.0 & 27.6 & 1.679 \\
\hline
\end{tabular}

SMR single-marker regression, CIM composite interval mapping, MIM multiple interval mapping

${ }^{a} R^{2}$ was the percentage of the phenotype variance explained by the QTL

b The estimated additive effect of the alleles of 'Jidou 12'

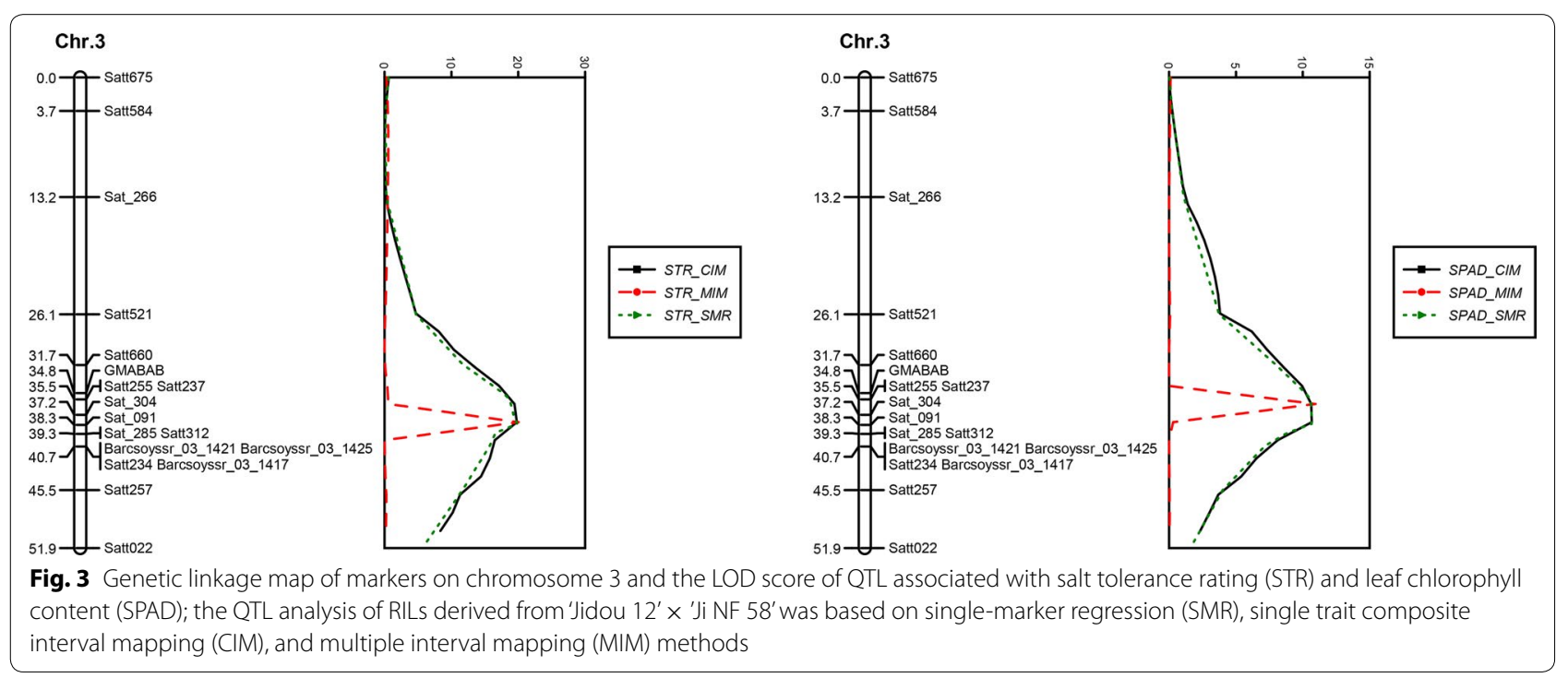

effect of this QTL was 1.634. For SPAD using CIM, this QTL was flanked by SSR markers GMABAB and Barcsoyssr_03_1421 and was closely linked with SSR marker Sat_091. The LOD was 10.7, and the QTL could explain $27.0 \%$ of the total phenotype variance. The additive effect of this QTL was 1.637. For SPAD using MIM, this QTL was closely linked with Satt237 and Satt255. The LOD was 11.0, and the QTL could explain $27.6 \%$ of the total variance. The additive effect of this QTL was 1.679.

The salt tolerance of the population ('Jidou 12' $\times$ 'Ji NF $58^{\prime}$ ) was tested using STR and SPAD. Based on the phenotype distribution analysis, transgressive segregation of both STR and SPAD were observed in this population. There were 43 and 71 lines that expressed lower salt tolerance than their sensitive parent 'Ji NF 58' in terms of STR and SPAD values, respectively. Additionally, there were 33 and 16 lines that expressed higher salt tolerance than 'Jidou 12' in terms of STR and SPAD values, respectively. These results implied that there should be more than one gene controlling salt tolerance in this population. However, only one major QTL, explaining $27-44 \%$ of phenotypic variance, was identified as a result of the mapping study. In another study, a similar result was observed in the populations of 'FT-Abyara' $\times$ 'C01' and 'Jin dou No. 6' × '0197'. In both cases, transgressive segregation was observed while only one QTL was identified [11]. It could be inferred that the lack of precise evaluation of salt tolerance was the major reason for these results, for which environmental effects and random error could be responsible. Two reasons for this lack of precision are that salt concentration has a gradient in both horizontal and vertical directions and human error while conducting the experiment [11]. To enhance the effectiveness of salt tolerance breeding, MAS was recommended for use in commercial breeding. There is a strong relationship between marker alleles and salt tolerance [10]; therefore, MAS will help compensate for the reduced precision in evaluating lines for salt tolerance. 
In this study, a major QTL conditioning salt tolerance on chromosome 3 was identified using SMR, CIM, and MIM mapping methods. Several linkage and association analysis [7-13] experiments, consisting of different study populations, strongly suggested that this QTL is stable. Meanwhile, this QTL has great application value. Lee et al. [10] examined the association between the salt tolerance and the flanking marker alleles of salt tolerance QTL in US cultivars descending from S-100 through 60 years of breeding by pedigree tracking. As a result, alleles at the Sat_091 and Satt237 loci from S-100 is always associated with salt tolerance in descendants. Following other research of soybean salt tolerance, our study has two contributions for soybean breeding. First, the QTL and its linked markers identified in this study are helpful to MAS in developing salt tolerant soybean cultivars.

This will assist in developing salt tolerant soybean cultivars that produce high yield, high protein content, and high oil content for the Huanghuaihai region in China, to which the parents of this study are well adapted. 'Jidou 12 ' has often been used as a parent in soybean breeding and at least four cultivars were released in China. At least three other sister lines of 'Ji NF 58' were released in the last decade. The second contribution of this study is that the salt tolerant parent 'Jidou 12' should contain a novel salt tolerant allele on chromosome 3 because there was no common parent found in other studies.

It has been reported that the gene under this QTL should be GmSALT3, and Glyma03g32900 was regarded as the candidate causal gene underlying GmSALT3, based on the analysis of the soybean reference genome obtained from Williams 82. Higher expression of the Glyma03g32900 in the soybean root resulted in lower accumulations of $\mathrm{Na}^{+}, \mathrm{K}^{+}$, and $\mathrm{Cl}^{-}$in the shoot under salt stress and showed significantly higher root fresh weights than the control. Transfer of Glyma03g32900 through Agrobacterium-mediated transformation into a soybean cultivar significantly enhanced its salt tolerance $[9,13,28,29]$. In this study, the QTL was mapped to a narrowed region on chromosome 3 containing Glyma03g32900, based on the sequence of Williams 82 [30]. This result suggested that Glyma03g32900 should also be the gene controlling salt tolerance in 'Jidou 12'. To ensure the validity of the candidate gene, the expression difference of Glyma03g32900 between the parents and the progeny, segregating for salt tolerance and sensitivity, should be examined.

\section{Conclusion}

The QTL for STR and SPAD was consistently identified on the soybean chromosome 3 , and identification of the DNA markers closely associated with the QTLs will significantly improve the efficiency in selecting for salt tolerance in soybean.

\section{Additional file}

Additional file 1: Table S1. 118 polymorphic SSR markers used in the 'Jidou $12^{\prime} \times$ 'Ji NF 58' population.

\begin{abstract}
Abbreviations
QTL: quantitative trait locus; RIL: recombinant inbred lines; STR: salt tolerance rating; SPAD: leaf chlorophyll content; MAS: marker-assisted selection; SMR: single-marker regression; CIM: composite interval mapping; MIM: multiple interval mapping.
\end{abstract}

\section{Authors' contributions \\ XLS LY, CYY designed the research proposal, analyzed the data and drafted the manuscript. WWY, TW, BQL, RD performed the laboratory work and collected data. DOM, PYC critically revised and edited the manuscript. MCZ planned the study and reviewed the final version of manuscript before submission. All authors read and approved the final manuscript.}

\section{Author details}

${ }^{1}$ Institute of Cereal and Oil Crops, Hebei Academy of Agricultural and Forestry Sciences/Shijiazhuang Branch Center of National Center for Soybean Improvement/Huang-Huai-Hai Key Laboratory of Biology and Genetic Improvement of Soybean, Ministry of Agriculture/Key Laboratory of Crop Genetics and Breeding, Shijiazhuang 050035, China. ${ }^{2}$ Department of Crop, Soi and Environment Sciences, University of Arkansas, Fayetteville, AR 72701, USA.

\section{Acknowledgements}

Not applicable.

\section{Competing interests}

The authors declare that they have no competing interests.

\section{Availability of data and materials}

The datasets used and/or analysed during the current study are available from the corresponding author on reasonable request.

\section{Consent for publication}

Not applicable.

Ethics approval and consent to participate

Not applicable.

Funding

This study was financially supported by National Natural Science Foundation of China (31201234, 31340043, 31471522 and 31000719), China Agriculture Research System (CARS-004-PS06), the Financial Foundation of Heibei Province (F13E006) and Postdoctoral Science Foundation of Heibei Province (B2012003).

\section{Publisher's Note}

Springer Nature remains neutral with regard to jurisdictional claims in published maps and institutional affiliations.

Received: 17 December 2015 Accepted: 23 January 2018 Published online: 05 February 2018

References

1. Yamaguchi T, Blumwald E. Developing salt-tolerant crop plants: challenges and opportunities. Trends Plant Sci. 2005;10:615-20.

2. Munns R, Tester M. Mechanisms of salinity tolerance. Annu Rev Plant Biol. 2008:59:651-81. 
3. Wang D, Shannon MC. Emergence and seedling growth of soybean cultivars and maturity groups under salinity. Plant Soil. 1999;214:117-24.

4. Singleton PW, Bohlool BB. Effect of salinity on nodule formation by soybean. Plant Physiol. 1984;74:72-6.

5. Phang TH, Shao G, Lam HM. Salt tolerance in soybean. J Integr Plant Biol. 2008;50:1196-212.

6. Parker MB, Gascho GJ, Gaines TP. Chloride toxicity of soybeans grown on Atlantic coast flatwoods soils. Agron J. 1983;75:439-43.

7. Ha B-K, Vuong TD, Velusamy V, Nguyen HT, Shannon JG, Lee J-D. Genetic mapping of quantitative trait loci conditioning salt tolerance in wild soybean (Glycine soja) PI 483463. Euphytica. 2013;193:79-88.

8. Hamwieh $\mathrm{A}, \mathrm{Xu} \mathrm{DH}$. Conserved salt tolerance quantitative trait locus (QTL) in wild and cultivated soybeans. Breed Sci. 2008;58:355-9.

9. Qi XP, Li MW, Xie M, Liu X, Ni M, Shao G, et al. Identification of a novel salt tolerance gene in wild soybean by whole-genome sequencing. Nat Commun. 2014. https://doi.org/10.1038/ncomms5340.

10. Lee GL, Carter T Jr, Villagarcia MR, Li Z, Zhou X, Gibbs MO, et al. A major QTL conditioning salt tolerance in S-100 soybean and descendent cultivars. Theor Appl Genet. 2004;109:1610-9.

11. Hamwieh A, Tuyen DD, Cong H, Benitez ER, Takahashi R, Xu DH. Identification and validation of a major QTL for salt tolerance in soybean. Euphytica. 2011;179:451-9.

12. Guan RX, Chen JG, Jiang JH, Liu GY, Liu Y, Tian L, et al. Mapping and validation of a dominant salt tolerance gene in the cultivated soybean (Glycine max) variety Tiefeng 8. Crop J. 2014;2:358-65.

13. Guan RX, Qu Y, Guo Y, Yu LL, Liu Y, Jiang JH, et al. Salinity tolerance in soybean is modulated by natural variation in GmSALT3. Plant J. 2014;80:937-50.

14. Chen HT, Cui SY, Fu SX, Gai JY, Yu DY. Identification of quantitative trait loci associated with salt tolerance during seedling growth in soybean (Glycine max L.). Crop Pasture Sci. 2008:59:1086-91.

15. Liu G, Guan RX, Chang RZ, Qiu LJ. Correlation between $\mathrm{Na}^{+}$content in different organs of soybean and salt tolerance at the seeding stage. Acta Agronomica Sinica. 2011;37:1266-73.

16. LiYH, Zhao SC, Ma JX, Li D, Yan L, Li J, et al. Molecular footprints of domestication and improvement in soybean revealed by whole genome re-sequencing. BMC Genom. 2013. https://doi. org/10.1186/1471-2164-14-579.

17. Guo Y, Li YH, Hong HL, Qiu L. Establishment of the integrated applied core collection and its comparison with mini core collection in soybean (Glycine max). Crop J. 2014;2:38-45.
18. Yan L, Li YH, Yang CY, Ren SX, Chang RZ, Zhang MC, et al. Identification and validation of an over-dominant QTL controlling soybean seed weight using populations derived from Glycine max x Glycine soja. Plant Breed. 2014;133:632-7.

19. Yan L, Xing LL, Yang CY, Chang RZ, Zhang MC, Qiu LJ. Identification of quantitative trait loci associated with soybean seed protein content using two populations derived from crosses between Glycine max and Glycine soja. Plant Genet Resour. 2014;12:S104-8.

20. Bai L, Li K, Chen YZ, Zhi HJ, Gai JY, Yang QH, et al. Evaluation of resistance to SMV of cultivars from soybean national local regional test. Chin J Oil Crop Sci. 2007;29:86-9.

21. Tuyen DD, Lal SK, Xu DH. Identification of a major QTL allele from wild soybean (Glycine soja Sieb. \& Zucc.) for increasing alkaline salt tolerance in soybean. Theor Appl Genet. 2010;121:229-36.

22. Cregan PB, Jarvik T, Bush AL, Shoemaker RC, Lark KG, Kahler AL, et al. An integrated genetic linkage map of the soybean genome. Crop Sci. 1999;39:1464-90.

23. Song QJ, Marek LF, Shoemaker RC, Lark KG, Concibido VC, Delannay X, et al. A new integrated genetic linkage map of the soybean. Theor Appl Genet. 2004;109:122-8.

24. Song QJ, Jia GF, Zhu YL, Grant D, Nelson RT, Hwang EY. Abundance of SSR motifs and development of candidate polymorphic SSR markers (BARCSOYSSR_1.0) in soybean. Crop Sci. 2010;50:1950-60.

25. Wang LX, Guan Y, Guan RX, Li YH, Ma YS, Dong ZM, et al. Establishment of Chinese soybean Glycine max core collections with agronomic traits and SSR markers. Euphytica. 2006;151:215-23.

26. Nelson JC. QGENE software for marker-based genomic analysis and breeding. Mol Breed. 1997;3:239-45

27. Voorrips R. MapChart: software for the graphical presentation of linkage maps and QTLs. J Hered. 2002;93:77-8.

28. Patil G, Do T, Vuong TD, Valliyodan B, Lee JD, Chaudhary J, et al. Genomicassisted haplotype analysis and the development of high-throughput SNP markers for salinity tolerance in soybean. Sci Rep UK. 2016. https:// doi.org/10.1038/srep19199.

29. Do TD, Chen HT, Vu HTT, Hamwieh A, Yamada T, Sato T, et al. NCl synchronously regulates $\mathrm{Na}^{+}, \mathrm{K}^{+}$, and $\mathrm{Cl}^{-}$in soybean and greatly increases the grain yield in saline field conditions. Sci Rep UK. 2016. https://doi. org/10.1038/srep19147.

30. Schmutz J, Cannon SB, Schlueter J, Ma J, Mitros T, Nelson W, et al. Genome sequence of the palaeopolyploid soybean. Nature. 2010;463:178-83.

\section{Submit your next manuscript to BioMed Central and we will help you at every step:}

- We accept pre-submission inquiries

- Our selector tool helps you to find the most relevant journal

- We provide round the clock customer support

- Convenient online submission

- Thorough peer review

- Inclusion in PubMed and all major indexing services

- Maximum visibility for your research

Submit your manuscript at www.biomedcentral.com/submit
(O) BioMed Central 